University of Montana

ScholarWorks at University of Montana

7-2009

\title{
Bushmeat Poaching Reduces the Seed Dispersal and Population Growth Rate of a Mammal-Dispersed Tree
}

Jedidiah F. Brodie

Olga E. Helmy

Warren Y. Brockelman

John L. Maron

University of Montana - Missoula, john.maron@mso.umt.edu

Follow this and additional works at: https://scholarworks.umt.edu/biosci_pubs

Part of the Biology Commons

Let us know how access to this document benefits you.

\section{Recommended Citation}

Brodie, Jedidiah F.; Helmy, Olga E.; Brockelman, Warren Y.; and Maron, John L., "Bushmeat Poaching Reduces the Seed Dispersal and Population Growth Rate of a Mammal-Dispersed Tree" (2009). Biological Sciences Faculty Publications. 248.

https://scholarworks.umt.edu/biosci_pubs/248

This Article is brought to you for free and open access by the Biological Sciences at ScholarWorks at University of Montana. It has been accepted for inclusion in Biological Sciences Faculty Publications by an authorized administrator of ScholarWorks at University of Montana. For more information, please contact scholarworks@mso.umt.edu. 


\title{
Bushmeat poaching reduces the seed dispersal and population growth rate of a mammal-dispersed tree
}

\author{
Jedediah F. Brodie, ${ }^{1,3}$ Olga E. Helmy, ${ }^{1}$ Warren Y. Brockelman, ${ }^{2,4}$ and John L. Maron ${ }^{1}$ \\ ${ }^{1}$ Division of Biological Sciences, University of Montana, Missoula, Montana 59812 USA \\ ${ }^{2}$ Center for Conservation Biology, Institute of Science and Technology for Research and Development, Mahidol University, \\ Salaya, Phuttthamonthon 4 Road, Nakhon Pathom 73170 Thailand
}

\begin{abstract}
Myriad tropical vertebrates are threatened by overharvest. Whether this harvest has indirect effects on nonhunted organisms that interact with the game species is a critical question. Many tropical birds and mammals disperse seeds. Their overhunting in forests can cause zoochorous trees to suffer from reduced seed dispersal. Yet how these reductions in seed dispersal influence tree abundance and population dynamics remains unclear. Reproductive parameters in long-lived organisms often have very low elasticities; indeed the demographic importance of seed dispersal is an open question. We asked how variation in hunting pressure across four national parks with seasonal forest in northern Thailand influenced the relative abundance of gibbons, muntjac deer, and sambar deer, the sole dispersers of seeds of the canopy tree Choerospondias axillaris. We quantified how variation in disperser numbers affected $C$. axillaris seed dispersal and seedling abundance across the four parks. We then used these data in a structured population model based on vital rates measured in Khao Yai National Park (where poaching pressure is minimal) to explore how variation in illegal hunting pressure might influence $C$. axillaris population growth and persistence. Densities of the mammals varied strongly across the parks, from relatively high in Khao Yai to essentially zero in Doi Suthep-Pui. Levels of $C$. axillaris seed dispersal and seedling abundance positively tracked mammal density. If hunting in Khao Yai were to increase to the levels seen in the other parks, C. axillaris population growth rate would decline, but only slightly. Extinction of C. axillaris is a real possibility, but may take many decades. Recent and ongoing extirpations of vertebrates in many tropical forests could be creating an extinction debt for zoochorous trees whose vulnerability is belied by their current abundance.
\end{abstract}

Key words: Choerospondias axillaris; frugivory; hunting; interspecific interaction; lar gibbon; mutualism; overharvest; red muntjac; sambar deer; Thailand.

\section{INTRODUCTION}

Overharvest is one of the most serious threats to tropical vertebrates worldwide (Robinson and Bennett 2000, Fa and Peres 2001, Milner-Gulland et al. 2003). "Bushmeat" hunting can reduce or eliminate mammals and birds in impacted areas (Robinson and Bennett 2000, Peres and Palacios 2007), leading to forests that are structurally intact but empty of large animals (Redford 1992). Indeed hunting rates of large vertebrates across the tropics are often so high as to be unsustainable (Fa et al. 2001, Bennett and Rao 2002, Milner-Gulland et al. 2003, Corlett 2007).

Although the direct effects of harvest on target species are of growing concern and have received considerable

Manuscript received 22 May 2008; accepted 25 September 2008. Corresponding Editor: E. Cuevas.

${ }^{3}$ Present address: David H. Smith Conservation Research Fellow, Wildlife Biology Program, University of Montana, 1134 Taylor Street, Missoula, Montana 59802 USA.

E-mail: jedediah.brodie@gmail.com

${ }^{4}$ Present address: Ecology Laboratory, Biotec Central Research Unit, Science Park, Klongluang, Pathum Thani, Thailand 12120. attention, hunted species represent only a small portion of the total biodiversity in any ecosystem. A critical, though largely unresolved, issue concerns the extent to which this harvest has cascading indirect effects that threaten nonhunted organisms (Springer et al. 2003, Frank et al. 2005), especially in complex tropical forests (Redford 1992, Brechin et al. 2003). Much of what we know about the indirect impacts of overharvest stems from marine systems where harvest is largely legal and measurable (Baum et al. 2003, Myers and Worm 2003, Frank et al. 2005). But in tropical terrestrial systems, most vertebrate harvest is illegal and extremely difficult to quantify. The annual black-market trade in wildlife is estimated at U.S. $\$ 8$ billion, second only to the illegal traffic of drugs and arms (WCS 2002).

We do know that hunting in tropical forests can drastically reduce animal populations (O'Brien and Kinnaird 2000, Peres 2000, Peres and Palacios 2007), and that many of these hunted species are frugivores that disperse tree and shrub seeds (Redford 1992, Chapman and Chapman 1995, Stoner et al. 2007a,b). Indeed frugivores comprise the bulk of vertebrate biomass in some tropical forests (Gautier-Hion et al. 


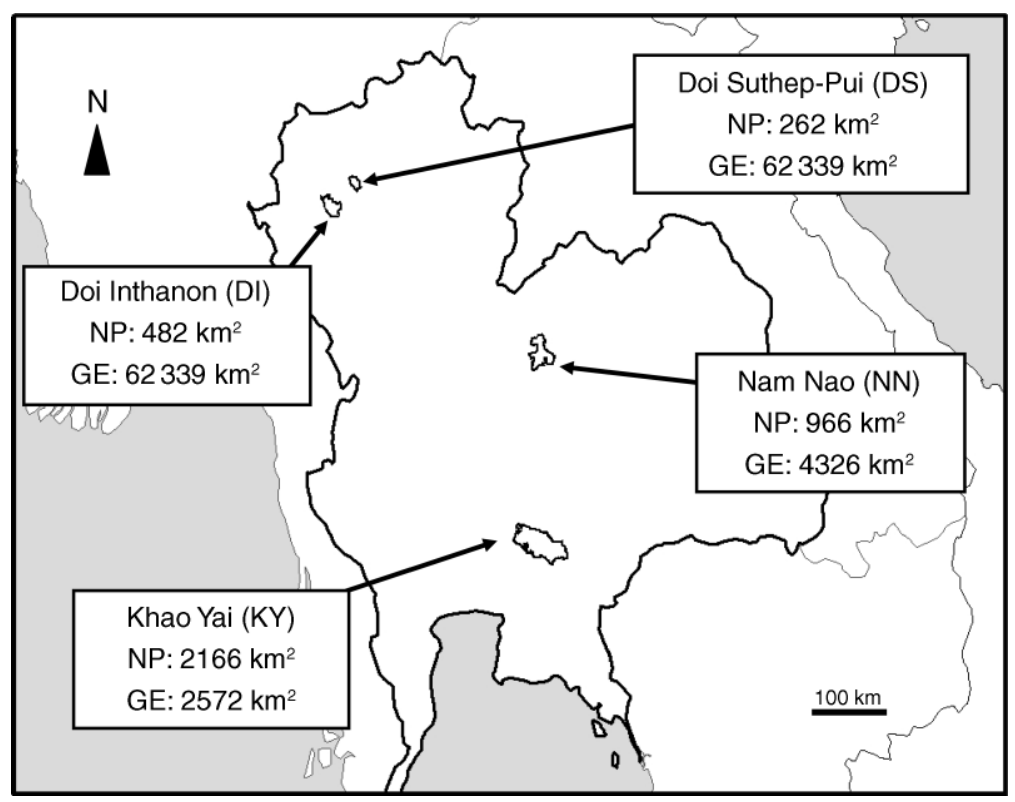

FIG. 1. Northern Thailand showing locations of the four national parks studied, with the area of the park (NP) and the greater ecosystem (GE) within which it resides (Leimgruber et al. 2003).

1985, Peres 1999), up to $85 \%$ of the total bird and mammal biomass at one site in Mexico (Estrada et al. 1993). As many as 70-90\% of tree species in these habitats are adapted for animal-mediated seed dispersal (Howe 1977, Gautier-Hion et al. 1985). Yet the cascading impacts of hunting on zoochorous seed dispersal are only beginning to be explored (Stoner et al. 2007a, $b$, Wright et al. 2007).

Although overhunting can reduce fruit removal (Wright et al. 2000, Wright and Duber 2001, Forget and Jansen 2007, Wang et al. 2007) and seed dispersal distances (Chapman and Onderdonk 1998), we have very little understanding of its impact on tree population dynamics. Largely this is because the demographic effects of seed dispersal itself are still poorly understood. On the one hand, reduced seed dispersal can lead to lower overall germination in a given fruit crop (Chapman and Chapman 1995, Forget and Jansen 2007). But on the other hand, the chances that any individual seed (dispersed or not) will survive to become a reproductive adult are extraordinarily slim (Howe and Smallwood 1982). Seed dispersal and seedling establishment often have very low elasticities, or low ability, relative to other vital rates, to affect population dynamics (Silvertown et al. 1993, Howe and Mariti 2004). This is especially true for long-lived organisms such as tropical trees, where population change is nearly always driven by adult survival rather than reproduction or the survival of younger age classes (Pfister 1998). Therefore, to address the potentially cascading indirect effects of overhunting on animal-dispersed trees, we must place alterations in seed dispersal and seedling establishment in a population-level context.
We capitalized on large-scale variation in poaching pressure across four national parks in northern Thailand (Fig. 1) to examine how reductions in several mammalian frugivore species might influence the recruitment and population growth rate of Choerospondias axillaris (Roxb.) Burtt \& Hill (Anacardiaceae), a widespread canopy tree. We surveyed four parks that protect tropical seasonal mixed-evergreen forest, including populations of $C$. axillaris. These parks vary in their abundance of lar gibbons (Hylobates lar), sambar deer (Rusa unicolor; syn. Cervus unicolor), and red muntjac (Muntiacus muntjak), the tree's primary seed dispersers in Thailand (Kunsakorn 2001). We measured the relative population density of these mammals in each park, and quantified levels of seed dispersal and seedling abundance of $C$. axillaris. We then used a stagestructured population model, based on demographic data collected in Khao Yai, to ask how $C$. axillaris population growth and persistence in Khao Yai would be affected if hunting were to increase (and C. axillaris seed dispersal correspondingly decrease) to levels observed in the other parks.

\section{Methods}

\section{Study sites}

Prior to extensive deforestation, northern Thailand was dominated by seasonal (or "monsoon") forests; many trees are deciduous or semi-deciduous (Gardner et al. 2000, Maxwell and Elliott 2001). The southwest monsoon usually occurs from May or June through October or November, and there is a pronounced dry season from December to March (Smitinand 1977, Maxwell and Elliott 2001). Doi Suthep-Pui (DS; $18^{\circ} 48^{\prime}$ 
$\mathrm{N}, 98^{\circ} 55^{\prime} \mathrm{E}$ ) is the most recently established of the four parks we surveyed, and the smallest. Most of the park lies on a $350-1685 \mathrm{~m}$ mountain with two peaks; the study sites were located in mixed evergreen-deciduous forest at mid-elevations near the center of the park where Choerospondias axillaris is considered of "medium abundance" (Maxwell and Elliott 2001). Mean annual rainfall is $\sim 2095 \mathrm{~mm}$ (Maxwell and Elliott 2001). The outskirts of Chiang Mai, one of Thailand's largest cities, lie only a few kilometers from the border of Doi SuthepPui, and at least four villages of ethnic Hmong people live inside the national park ( $\sim 5000$ individuals in 1999), practicing agriculture and illegal hunting (Maxwell and Elliott 2001). Nearly all large birds (Round 1984) and mammals (Maxwell and Elliott 2001) have been extirpated from the park by overhunting, including sambar and gibbons; muntjac remain extant but very rare (Maxwell and Elliott 2001). Doi Inthanon National Park (DI; $18^{\circ} 32^{\prime} \mathrm{N}, 98^{\circ} 33^{\prime} \mathrm{E}$ ) is larger than DS and within the same topographic zone and forest complex (Leimgruber et al. 2003). It also has villages inside its boundaries (Hmong and Karen people), with attendant hunting and some illegal forest conversion. None of our study sites were affected by forest conversion (though a C. axillaris tree on one of our plots was poached after the study concluded). Gibbons (along with many other large mammals and birds) are almost certainly extirpated from this park; sambar and muntjac are uncommon (J. F. Brodie, personal observation). Nam Nao National Park (NN; $\left.16^{\circ} 44^{\prime} \mathrm{N}, 101^{\circ} 34^{\prime} \mathrm{E}\right)$ is in the somewhat drier eastern plateau. Much of the forests are relatively open and dominated by Dipterocarpus, Pinus, and Quercus species (J. F. Brodie, personal observation); there are also extensive patches of mixed evergreen-deciduous forest (in wetter areas), in which we located our study plots. Nam Nao is bisected by a major highway and several smaller roads. Little is known about its hunting pressure or mammal densities; sambar and muntjac appear relatively common though gibbon abundance is likely very low (J. F. Brodie, personal observation). Khao Yai (KY; $14^{\circ} 26^{\prime} \mathrm{N}, 101^{\circ} 22^{\prime} \mathrm{E}$ ) is Thailand's oldest and one of its largest parks. It lies on a large plateau, $700-900 \mathrm{~m}$ in elevation, dominated by mixed evergreen-deciduous forests (Smitinand 1977). Annual rainfall is $\sim 2500 \mathrm{~mm}$. Khao Yai is nearly surrounded by towns and villages, but the steep slopes on the flanks of the plateau make access to the interior on foot difficult. There are no villages (other than park staff quarters) inside the park, and the small roads that cross the park are guarded by entry kiosks. Poaching is rife on the periphery of the park, but the density of many large mammals in the central portion of the park is quite high (Lynam et al. 2006), suggesting a more limited impact of poachers. Deer, gibbons, large birds such as hornbills (Bucerotidae), and sign of elephant (Elephas maximus) are observed almost daily in Khao Yai, unlike in any of the other parks (J. F. Brodie, personal observation). A 30-ha forest biodynamics plot was initiated in 1994 in the central western portion of the park ("Mo Sing To" area). The first complete census of all woody stems $\geq 1$ $\mathrm{cm}$ in diameter was completed in 2005.

\section{Field sampling}

In 2002, we established four plots each in Khao Yai and Doi Suthep-Pui. In 2003 these were resurveyed, and four plots each established in Doi Inthanon and Nam Nao. All plots were resurveyed in 2004. Each plot was 50 $\times 100 \mathrm{~m}$ and separated from others in the same park by 1-4 km; plots in Khao Yai were located systematically, and in other parks were placed in areas that resembled the Khao Yai plots as closely as possible in terms of topography, forest type, and adult C. axillaris density. We estimated the fruit crop on all trees in the plots by counting fruits on a portion of each tree's canopy using $8 \times 40$ binoculars (cf. Milton 1991, Tutin and Fernandez 1993, Tapper 1996) and dividing this count by the proportion of the canopy sampled. We estimated the $C$. axillaris fruit crop on all adult female trees per plot at the beginning (July) of the fruiting season to determine the available fruit crop on each sampling plot. At the end of the fruiting season (October) we measured the proportion of seeds that remained undispersed (i.e., were underneath or still on the parent tree). The distances over which $C$. axillaris seeds are dispersed is a function of movement and gut retention time in the frugivores which, being large-bodied, mobile mammals, could be quite high. Therefore seed deposition through the forest is essentially random with respect to location of the mother tree, and does not decay as a predictable function of distance from the fruiting female (J. F. Brodie, unpublished data), as it would with smaller frugivores or those that spit seeds rather than ingesting them (Bodmer 1991). Thus, to detect dispersed seeds, we established four parallel $50 \times 4 \mathrm{~m}$ transects randomly on each plot (away from the parent canopies and light gaps), instead of radiating out from mother tree trunks. We surveyed these at the end of each fruiting season to measure the density of seeds dispersed to the forest (shade dispersal). Current-year seeds could be easily distinguished in this species (and were the only ones we counted); older seeds exhibited extensive decay. Finally, because $C$. axillaris seedling establishment is enhanced in light gaps, we assessed the probability of seeds being dispersed to these particular microhabitats across our study sites. We randomly located three $10 \times 10 \mathrm{~m}$ plots in light gaps on each plot (or, if there were not three gaps on a plot, on the nearest gaps to the plot). Light gaps were defined as $<60 \%$ canopy cover (measured with a spherical densitometer) as this was an inflection point in seedling establishment probabilities (see Results and Fig. 5A). We surveyed these gaps for dispersed seeds (light gap dispersal) and seedlings at the end of each fruiting season.

We measured gibbon abundance using auditory sampling of their vocalizations, a standard method for surveying forest primates (Brockelman and Ali 1987, 
Brockelman and Srikosamatara 1993). At each plot, we measured the maximum number of groups heard calling during a one-hour period (starting between 06:00 and 07:00 hours) per day for five days. The mean maximum number of groups heard across five days was the gibbon abundance index. We measured relative abundance for muntjac and sambar using scat pellet counts (Bennett et al. 1940, Neff 1968) on the same transects used to measure seed dispersal levels. Transects were cleared of scat at the beginning of the season and sampled at the end. The relative abundance index was the total number of scat piles per plot divided by an experimentally determined "scat persistence rate" (Brodie 2006) at each plot.

In 2003 and 2004 we set up planting arrays on the Khao Yai forest biodynamics plot to assess seed predation and seedling establishment across deposition environments (15 sites over a range of canopy cover conditions, one-fourth of which were under adult female C. axillaris canopies). We used two cage types: "closed" to measure rates of seedling establishment and beetle predation and "open" to measure rates of seed predation by small mammals. Cages were made of wire with a 1$\mathrm{cm}^{2}$ mesh size; they should not have affected beetle predation because the beetles were only $\sim 1 \mathrm{~mm}$ long. Germination is not affected by seed handling (i.e., defecation vs. regurgitation vs. not ingested) (Kunsakorn 2001) so this effect was not tested. The numbers of remaining intact seeds (open cages) and seedlings (closed cages) were recorded the year following the initiation of each experiment. Thus "seedling establishment" as used here incorporates actual germination as well as survivorship of the seedlings over their first year. We also compared seedling establishment and seed predation across parks, using six open and six closed cages per plot, one-half in light gaps and one-half in the shade, each with $40 C$. axillaris seeds.

We marked naturally occurring seedlings $(n=668)$ on the Khao Yai forest biodynamics plot and followed their fates from 2003 to 2005 to assess survivorship and growth rates.

We also administered written (in Thai) questionnaires to a haphazard sample of 10 park rangers in each park (cf. Wright et al. 2000), asking them to qualitatively evaluate poaching pressure in their park and assess whether it had affected gibbon, sambar, and muntjac populations.

\section{Population model}

We assessed the importance of seed dispersal and its disruption for the population dynamics of $C$. axillaris using a stage-based, habitat-explicit matrix projection model. Much of the vital rate data for the model came from the Khao Yai forest biodynamics plot. The model was female-based and used a post-birth census with five stage classes: seedlings under mother trees, seedlings dispersed away from mother trees but in the shade ( $\geq 60 \%$ canopy cover), seedlings in light gaps $(<60 \%$ canopy cover), juveniles ( $>1.3 \mathrm{~m}$ tall), and adults $(>18$ $\mathrm{cm}$ diameter at breast height [dbh], the smallest diameter at which trees begin fruiting; W. Y. Brockelman, unpublished data). Only adults produced seeds, and there was no seed bank (J. F. Brodie, unpublished data).

The number of seedlings in habitat $i\left(\mathrm{sdlg}_{i}\right)$ produced by each adult per year was given by

$$
\operatorname{sdlg}_{i}=S_{\mathrm{A}} \times F_{\mathrm{A}} \times P_{\mathrm{F}} \times D_{i} \times M_{i}
$$

where $S_{\mathrm{A}}$ is the annual survivorship of adults (measured by repeat censuses on the biodynamics plot), $F_{\mathrm{A}}$ is the annual fecundity of adults (annual fruit counts of female trees on the biodynamics plot for 3 consecutive years), $P_{\mathrm{F}}$ is the proportion of seeds that are female (assumed to be the same as the measured sex ratio of adults on the biodynamics plot), $D_{i}$ is the proportion of fecundity dispersed to habitat $i$, and $M_{i}$ is the seedling establishment of seeds in habitat $i$ (measured experimentally in Khao Yai; see Fig. 5A). For the "under mother tree" habitat, $D_{i}$ was the proportion of seeds that remained undispersed (Fig. 4A); for the two dispersed habitats,

$$
D_{i}=\left(1-P_{\mathrm{U}}\right) \times\left(\frac{Y_{i}}{Y_{i}+Y_{j}}\right)
$$

where $P_{\mathrm{U}}$ is the proportion of seeds undispersed, $Y_{i}$ is the density of dispersed seeds in habitat $i$ (see Fig. $4 \mathrm{~B}, \mathrm{C}$ ), and $Y_{j}$ is the density of dispersed seeds in the other of the two "dispersed" habitats.

Seedlings in given habitats could die, survive and remain seedlings in that habitat, or transition to become juveniles. These transition rates $\left(J_{i}\right)$ were based on habitat-specific survival and growth rates (see Fig. $5 \mathrm{~B}, \mathrm{C})$ and the cutoff point $(Z)$ between seedlings and juveniles $(1.3 \mathrm{~m})$, and they accounted for size structure within the seedling stages (cf. Crouse et al. 1987):

$$
J_{i}=\frac{S_{s, i}^{\left(G_{s, i} / Z\right)-1} \times\left(1-S_{s, i}\right)}{1-S_{s, i}^{\left(G_{s, i} / Z\right)}}
$$

where $S_{s, i}$ and $G_{s, i}$ are the annual survival and growth, respectively, of seedlings in habitat $i$.

Survival of juveniles and adults, and the transition of juveniles to adults were estimated from repeat censuses of the forest biodynamics plot (W. Y. Brockelman, unpublished data).

As most of the vital rate data come from Khao Yai, we could not make any inference about $C$. axillaris population growth rates in other parks. Instead we used the matrix model to ask how, if hunting were to increase in Khao Yai to the levels observed in the other parks, would $C$. axillaris population growth be affected? For each of 10000 bootstrap iterations, we resampled (with replacement) from the raw data to estimate vital rates and build four matrices that were identical except for the seed dispersal terms (which varied according to seed dispersal levels observed in each park). We calculated the dominant eigenvalue of each matrix $(\hat{\lambda})$ and took the differences in growth rate $(\Delta \hat{\lambda})$ between the Khao Yai 


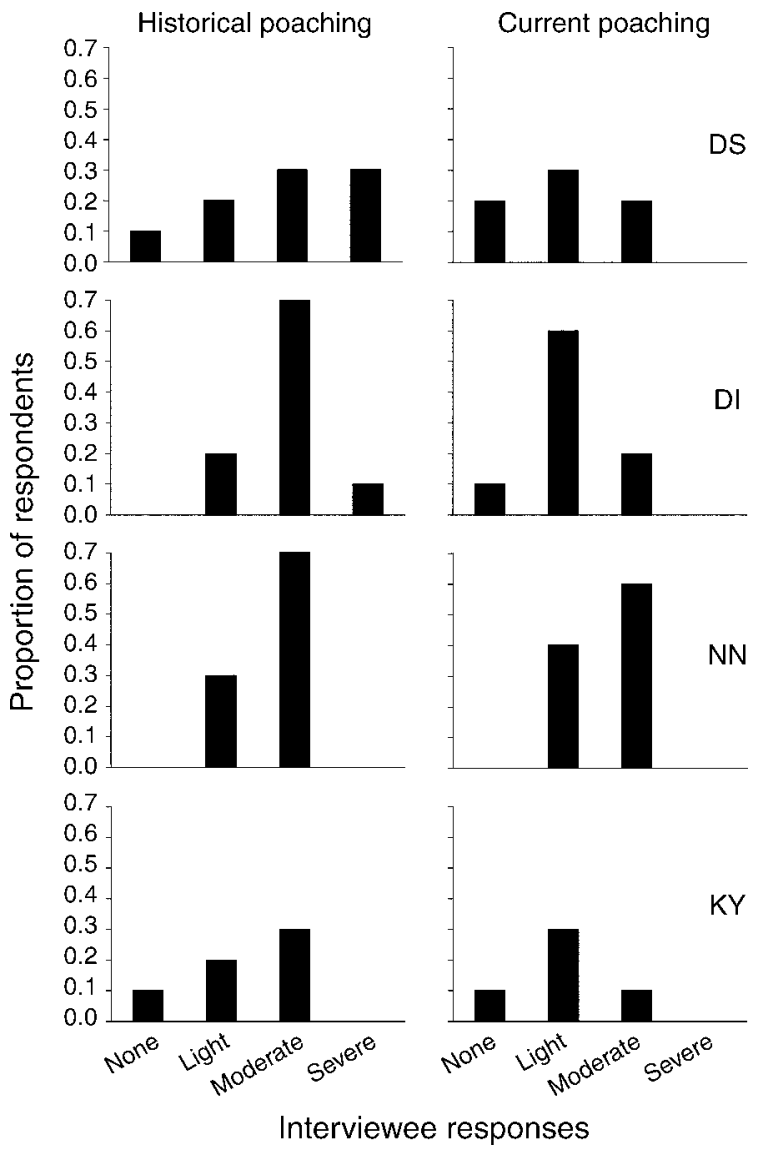

FIG. 2. Responses by park rangers interviewed in Doi Suthep-Pui (top row), Doi Inthanon (second row), Nam Nao (third row), and Khao Yai (bottom row), asked to qualitatively assess poaching pressure "since the park was formed" (left column) and "currently" (right column) on lar gibbons (Hylobates lar), red muntjac (Muntiacus muntjak), and sambar deer (Rusa unicolor).

matrix and each of the "increased hunting" matrices. These bootstrap $\Delta \hat{\lambda}$ arrays were ordered by rank and the 250th and 9750th used as lower and upper, respectively, 95\% confidence limits. We also calculated the exponential decay half-life of the population as

$$
T_{1 / 2}=\frac{\log _{e}(2)}{\log _{e}(\hat{\lambda})}
$$

to provide a simple metric for how changes in deterministic $\hat{\lambda}$ might affect population persistence.

\section{RESUlts}

\section{Field sampling}

Twice as many park rangers interviewed in Doi Suthep-Pui indicated that historical poaching had been "moderate" or "severe" as "light" or "none." In Khao Yai one-half of the respondents said that poaching had been moderate, the other half either light or none. In Doi Inthanon and Nam Nao, $70 \%$ of respondents said that poaching had been moderate. No rangers in any park indicated that current poaching was severe (see Fig. 2). There were no differences among the parks in terms of their respective rangers' assessments of historical gibbon, muntjac, or sambar abundance.

Relative density of the three mammals differed strongly among the parks in 2003 (gibbons, ANOVA, $F_{3,12}=520.273, P<0.001 ;$ muntjac, $F_{3,12}=11.910, P=$ 0.001 ; sambar, $\left.F_{3,12}=33.552, P<0.001\right)$ and 2004 (gibbons, $F_{3,12}=173.400, P<0.001 ;$ muntjac, $F_{3,12}=$ 9.428, $P=0.002$; sambar, $F_{3,12}=23.675, P<0.001$; see Fig. 3). Gibbons were consistently abundant in Khao

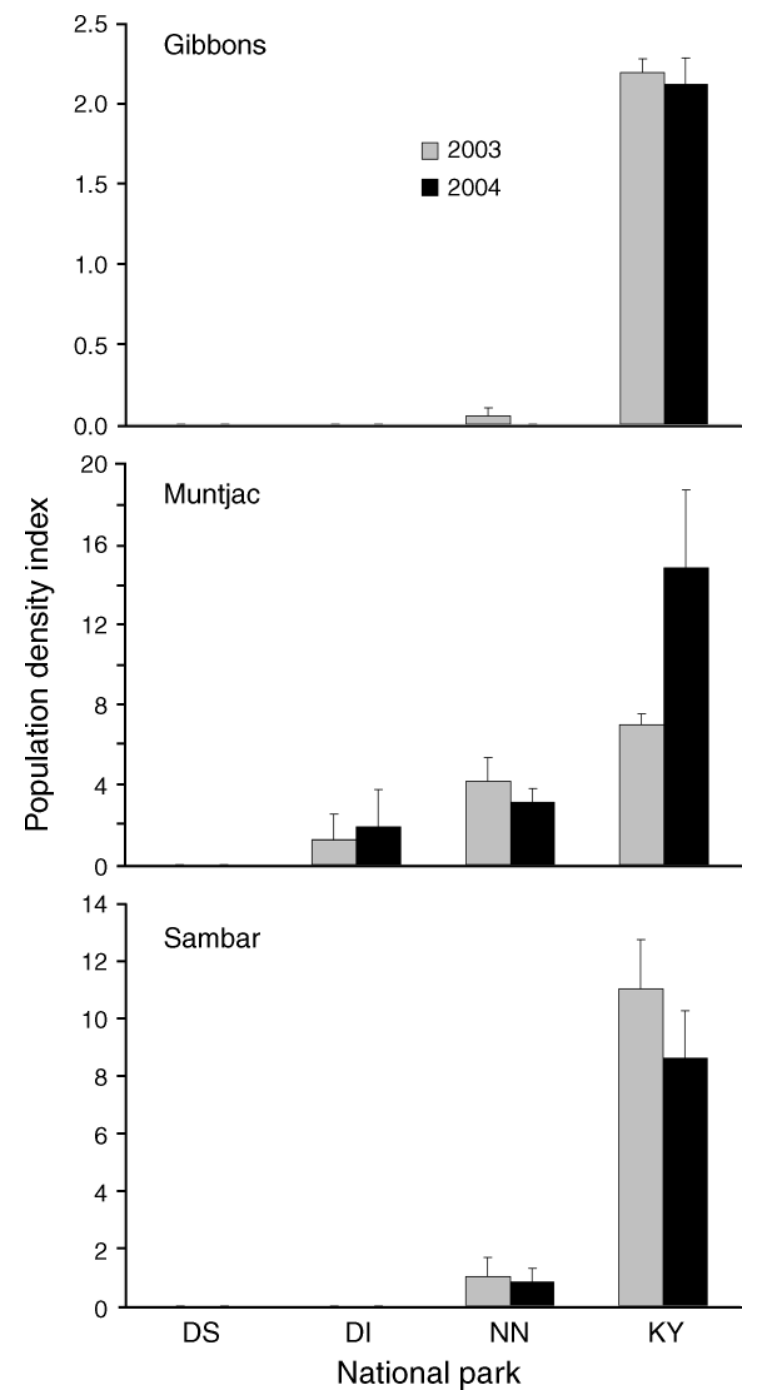

FIG. 3. Relative mammal density (mean $+\mathrm{SE}$ ) across parks for gibbons, muntjac, and sambar, the primary seed dispersers for the canopy tree Choerospondias axillaris in Thailand. Gibbon relative abundance was the maximum number of groups heard calling during a one-hour period, averaged over five days. Deer relative abundance was the total number of scat pellet piles deposited per $800 \mathrm{~m}^{2}$ of transects per plot, divided by an experimentally determined scat persistence rate (cf. Brodie 2006). Standard error bars show spatial variation across the four plots per park. 
Yai in both years and were never detected in Doi Suthep-Pui or Doi Inthanon; one group was heard calling once in Nam Nao (from very far off) in 2003, but none were detected in 2004. Muntjac and sambar densities were relatively high in Khao Yai and lower in Nam Nao; muntjac but not sambar were detected in Doi Inthanon. Neither of the deer were detected on our transects in Doi Suthep-Pui, though muntjac scat was observed on one occasion in that park.

The proportion of $C$. axillaris fruits remaining undispersed at the end of the field season (i.e., those that were still on or underneath the mother trees) differed strongly between parks in 2003 (ANOVA; $F_{3,38}$ $=24.68, P<0.001)$ and in $2004\left(F_{3,38}=13.22, P<\right.$ 0.001 ). The proportion of undispersed fruits ranged from $80 \%$ to $94 \%$ in Doi Suthep-Pui to $15 \%$ to $21 \%$ in Khao Yai (Fig. 4A). The density $\left(\mathrm{m}^{-2}\right)$ of seeds dispersed away from mother trees but remaining in the shade ( $\geq 60 \%$ canopy cover) varied significantly among parks in 2004 (ANOVA; $F_{3,12}=19.60, P<0.001$ ), but not in 2003. The density of seeds dispersed to light gaps varied significantly among parks in $2004\left(F_{3,12}=4.03, P\right.$ $=0.034$ ), but not in 2003 (Fig. 4). In general, the density of dispersed seeds and the proportion of undispersed seeds positively and negatively (respectively) track variation in mammal density across the parks, though our small sample size ( $n=4$ parks) precludes effective formal correlation analysis.

We pooled $C$. axillaris seedling density $\left(\mathrm{m}^{-2}\right)$ data within plots across all years because, unlike seeds (which were always from the current year fruit crop), seedlings could survive to be counted in consecutive years. The density of seedlings away from parent canopies but in the shade did not vary significantly among parks, but the density of seedlings in light gaps did $\left(F_{3,12}=6.07, P=\right.$ 0.009). Seedling density in light gaps was higher in Khao Yai than in any other park (Tukey post hoc comparisons; Doi Inthanon, $P=0.050$; Doi Suthep-Pui, $P=$ 0.010; Nam Nao, $P=0.026$ ). In Doi Suthep-Pui, where large mammals are all but extinct (but adult $C$. axillaris still remain common), no C. axillaris seeds or seedlings were found in light gaps. Seedling abundance could clearly be related to adult abundance. Yet, as mentioned before, we controlled for the latter by choosing study plots in Doi Suthep-Pui, Doi Inthanon, and Nam Nao that mimicked Khao Yai in adult abundance. There were no significant differences in adult $C$. axillaris abundance among parks in our study (based on the four plots in each park).

Seed seedling establishment in light gaps, determined experimentally in Khao Yai, was higher than in the shade (ANOVA, $F_{2,116}=8.31, P<0.001$; Fig. 5). Seedling establishment under adult females was zero in our experiments, but this is partly an experimental artifact because seedlings can be found under female trees in nature. There were no differences in rates of seed predation among habitats. Seedling growth was higher
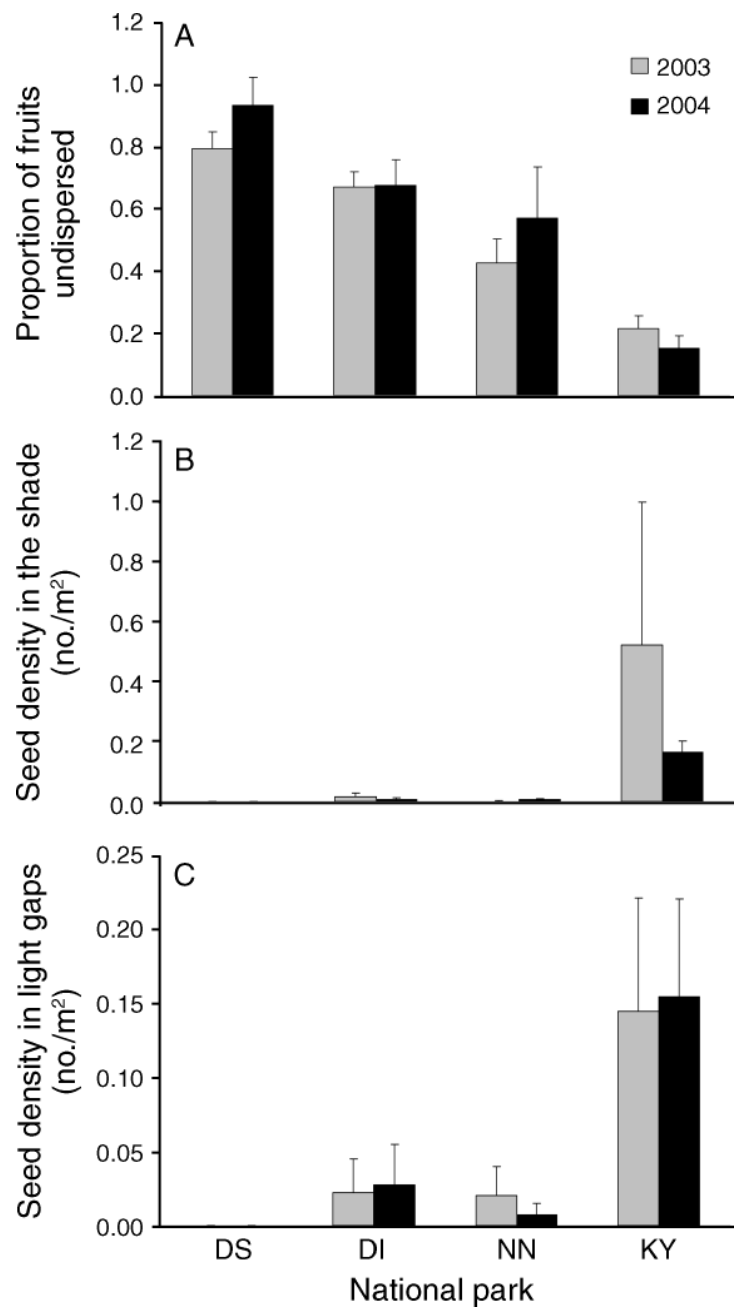

FIG. 4. (A) Proportion of Choerospondias axillaris fruits $($ mean + SE) left undispersed (still on or underneath the mother trees) at the end of the field seasons. Density of seeds dispersed away from mother trees is shown for dispersal (B) to shady habitats and (C) to light gaps.

in light gaps than in the shade or under mother trees (growth, $F_{2,88}=4.84, P=0.010$; Fig. 5).

Seed addition experiments showed no difference in seedling establishment rates across national parks, either in forest (ANOVA, $F_{3,44}=0.67, P=0.577$ ) or in light gaps $\left(F_{3,44}=0.12, P=0.947\right)$. Seed predation rates, measured with open cages to which rodents and insects had access to seeds, did vary across parks in the forest $\left(F_{3,43}=3.05, P=0.039\right)$ : they were lower in Nam Nao than in Doi Inthanon (Tukey post hoc comparison: $P=$ $0.050)$. They did not vary significantly in light gaps $\left(F_{3,44}\right.$ $=2.48, P=0.073$ ). Annual survivorship did not differ among parks for seedlings under parent trees $\left(F_{3,148}=\right.$ $1.15, P=0.332$ ), seedlings away from parent trees but still in the shade $\left(F_{1,38}=0.11, P=0.774\right)$, or seedlings in light gaps $\left(F_{2,78}=0.18, P=0.838\right)$. Surviving seedlings in the shade were too scarce in any park to test for 

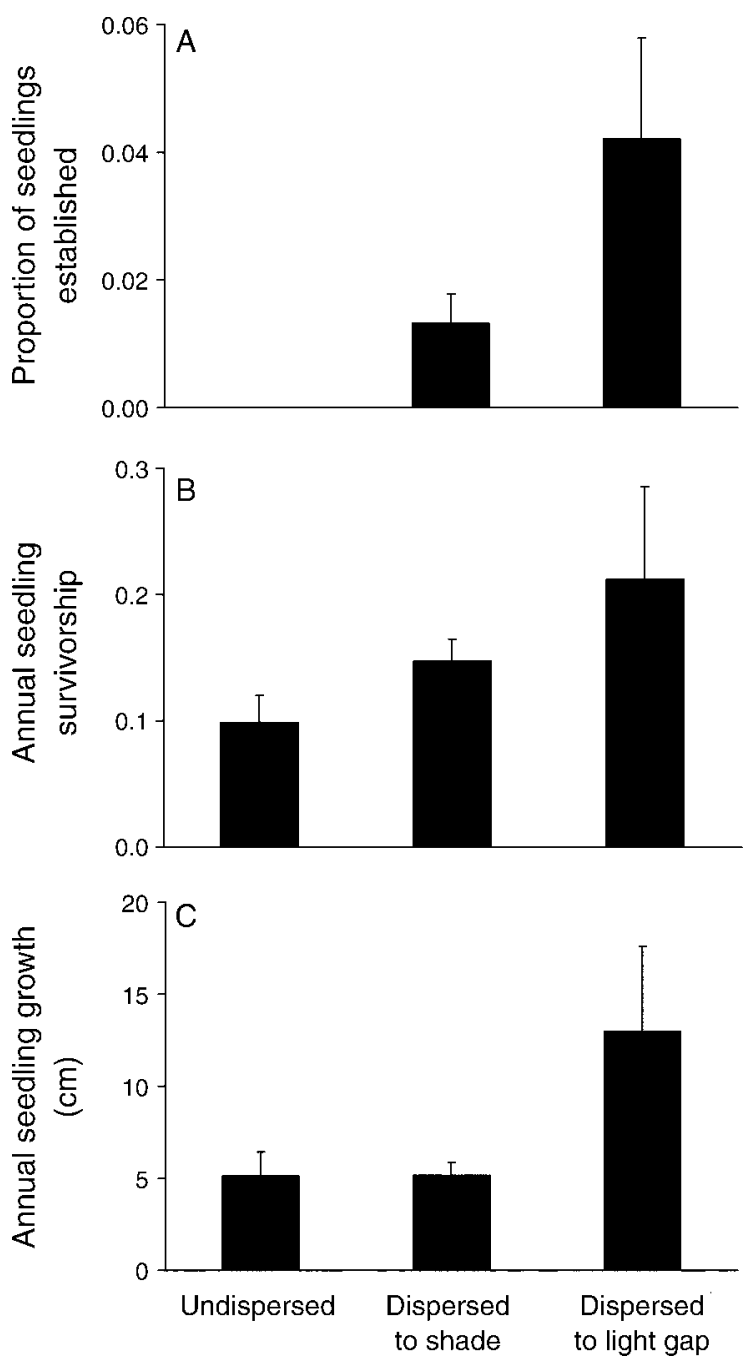

FIG. 5. (A) C. axillaris seedling establishment (mean $+\mathrm{SE}$ ), (B) seedling survivorship, and (C) seedling growth across habitats.

differences in their growth rates. Annual growth of seedlings under parent trees did not differ $\left(F_{3,13}=0.35\right.$, $P=0.793)$, though growth in light gaps $\operatorname{did}\left(F_{2,12}=7.16\right.$, $P=0.009$ ), due to lower rates in Khao Yai (mean $=7.96$ $\mathrm{cm} / \mathrm{yr}$ ) than in Doi Inthanon (mean $=10.00 \mathrm{~cm} / \mathrm{yr}, P=$ $0.009)$.

\section{Population model}

The mean C. axillaris population growth rate in Khao Yai was estimated at 0.990 . As seed dispersal declined across the increased hunting scenarios, the population growth rate dropped, though very slightly. Nam Nao seed dispersal levels reduced the Khao Yai $\hat{\lambda}$ by 0.003 (CL: $0.000,0.018$, all values are mean and 95\% CL), Doi Inthanon seed dispersal levels by 0.006 (CL: 0.000, 0.029), and Doi Suthep-Pui levels by 0.009 (CL: 0.000, 0.048; see Fig. 6). The exponential decay half-life for the Khao Yai $C$. axillaris population, based on the best- estimate $\lambda$, is 69.0 years. As seed dispersal and $\hat{\lambda}$ in the "increased hunting" scenarios decline, the population half-life is reduced by 17.2 years for Nam Nao hunting levels (CL: 0.0, 44.6), 24.6 years for Doi Inthanon hunting levels (CL: 0.0, 51.7), and 31.9 years for Doi Suthep-Pui levels (CL: 0.0, 57.3).

The analytical elasticity (sensu Caswell 2001) of seed dispersal (to all habitats combined) is the fourth highest $(0.014)$ out of 15 vital rates, following adult survivorship (0.792), juvenile survivorship (0.110), and the survivorship of seedlings in light gaps (0.034).

\section{Discussion}

Parks with extensive hunting exhibit lower seed dispersal and fewer C. axillaris seedlings. Gibbons, muntjac, and sambar in Khao Yai transport a high proportion of $C$. axillaris seeds away from the parent canopy, and some of them to light gaps, where seedling establishment and survival are enhanced. In the other parks, where the abundance of these mammals is lower, seed dispersal is curtailed; the density of seeds dispersed to the forest and to light gaps is lower and the proportion of seeds that remain undispersed is higher. The density of $C$. axillaris seedlings in light gaps positively tracks both gibbon and deer density and the level of seed dispersal to gaps.

Previous studies have shown that hunting in Neotropical and Afrotropical forests can disrupt seed dispersal mutualisms by reducing the quantity of seeds removed (Wright et al. 2000, Wright and Duber 2001, Forget and Jansen 2007, Wang et al. 2007) or the distances over which they are transported (Chapman and Onderdonk 1998). Our data corroborate these findings for a widespread canopy tree of the Indomalayan tropics, and place the results in a population-level context. In national parks with severe hunting, we estimate that the long-term population growth rate and the population persistence of $C$. axillaris are reduced, albeit slightly. Model output suggests that the disruption of this seed dispersal mutualism by illegal hunting of frugivorous mammals can lower the abundance and the time to extinction for this zoochorous tree.

Although our results suggest that reductions in frugivorous mammal abundance may decrease $C$. axillaris population growth, this decrease is slight; even a massive reduction in mammal density, from quite high in Khao Yai to essentially zero in Doi Suthep-Pui, results in only a very small drop in C. axillaris $\hat{\lambda}$ (see Fig. 6A). This is likely explained by the relatively low elasticity of seed dispersal. In other words, even if no regeneration were to go on at all, it would still take a very long time for the adults in the population to slowly fade from attrition. But the declines, though slow, are real. As mammalian frugivores are reduced or removed from tropical forests, the persistence and population dynamics of the trees that depend on them for seed dispersal may be affected, even if actual extinction could take many decades or longer. C. axillaris adults are still 
relatively common across the parks that we surveyed. But widespread extirpation of the tree's seed dispersers has, relative to the long lifespan of C. axillaris, occurred only recently. Impacts of seed disperser loss on $C$. axillaris demography are being felt; adult abundance will likely decline, possibly to extinction, in the foreseeable future. We suggest that overhunting of tropical frugivores could be creating an extinction debt, whereby adults of long-lived zoochorous trees may remain extant (sometimes even common), but slowly disappear through attrition as they fail to be replaced.

Because our study, like all others on the topic, uses a natural experiment rather than a controlled manipulation, we cannot exclude the possibility that factors other than hunting explain the variation in mammal abundance across these parks. The lowest relative abundance of all three mammals surveyed was in the smallest park, Doi Suthep-Pui. We think it unlikely, however, that the observed mammal abundances are strongly influenced by fragmentation effects (cf. Silva and Tabarelli 2000, Terborgh et al. 2001, Cordeiro and Howe 2003), since the parks are part of larger forest complexes (Fig. 1) that substantially increase their effective area (Leimgruber et al. 2003). There are no diseases or introduced species known to affect primate or deer populations in any of these parks. The high proportion of drier, more open forests in Nam Nao could account for the very low gibbon density there. But in the absence of hunting these forests should, if anything, support higher deer densities than closed-canopy moist tropical forest (Dinerstein 1982, Robinson and Bennett 2004). Indeed hunting pressure is often a better predictor than forest type for mammal density in tropical areas (Bennett et al. 2000). Likewise, Doi Suthep-Pui and Doi Inthanon have villages inside their boundaries, with some associated conversion of forest to agricultural fields; while this habitat alteration would undoubtedly have negative effects on the strictly arboreal gibbons, in the absence of hunting it should not be detrimental to the deer (Dinerstein 1982, Robinson and Bennett 2004). Hunting is known to be unsustainably high across Southeast Asia (WCS 2002, Lynam et al. 2006), to have caused the extirpation of large-bodied vertebrates within protected areas of northern Thailand (Round 1984, Maxwell and Elliott 2001, Tungittiplakorn and Dearden 2002, Lynam et al. 2006), and to be "... the greatest threat to wildlife and wild lands in Asia" (WCS 2002:31). Despite small sample sizes, our interviews suggest that historically, poaching in Khao Yai was less intense than in the other three parks.

Likewise, factors other than seed dispersal limitation could potentially explain the differences in $C$. axillaris seedling abundance across parks. Yet $C$. axillaris seedling establishment, seed predation, and seedling survivorship rates, determined experimentally, did not differ importantly among parks. Seedling growth was lower in Khao Yai than in Doi Inthanon, but clearly this cannot explain the higher seedling abundance in the

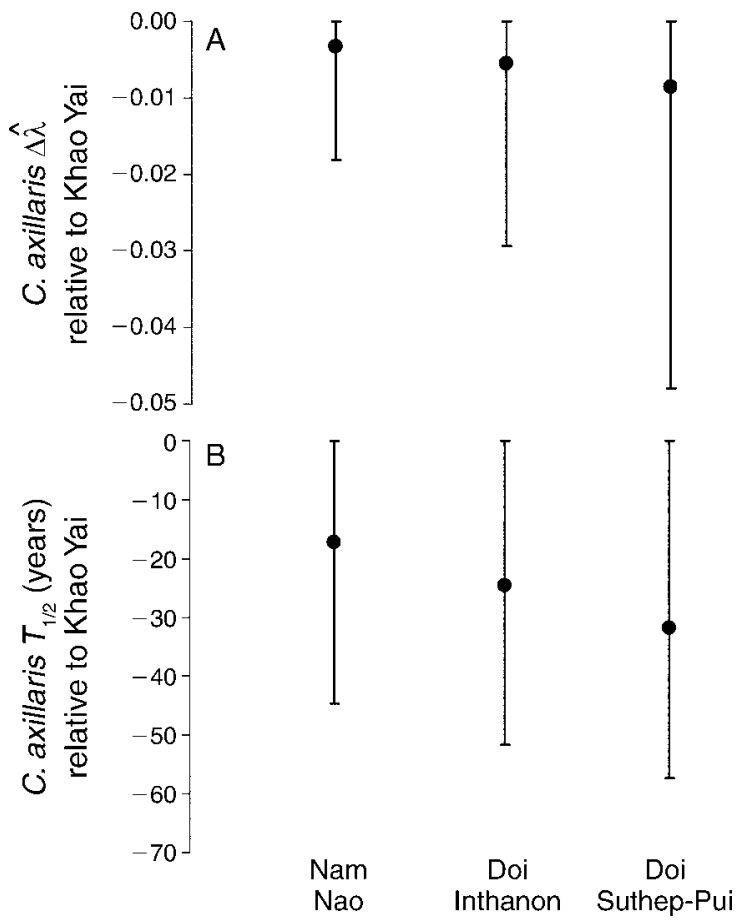

FIG. 6. Estimated change in (A) C. axillaris population growth rate and (B) exponential decay half-life in Khao Yai if hunting in that park were to increase (and seed dispersal to correspondingly decrease) to the levels seen in the other parks. Bootstrap mean and $95 \%$ confidence intervals are shown.

former. Though much of Nam Nao is drier than the other parks, the study sites in each park were broadly similar in forest type and density of C. axillaris adults.

We use a structured population model to assess the cascading effects of overhunting, and suggest that this approach can be highly valuable for evaluating the population-level consequences of mutualism disruptions in complex systems and on large geographic scales. However, inherent in this approach are several assumptions that may affect the robustness of its results. First, we assume that the only way for seeds to get to light gaps is to be dispersed there by animals, when in nature gaps can form (by falling trees or branches) above undispersed seeds. But a more detailed model that includes such habitat transitions results in only very slight $(<0.01 \%)$ changes in C. axillaris $\hat{\lambda}(\mathrm{J}$. F. Brodie, unpublished data). Second, the model does not incorporate environmental stochasticity or density dependence, both of which could influence population dynamics. Moreover some of the vital rates used to construct our model are based on relatively small sample sizes: two annual transitions for seedlings and repeat censuses three years apart for juveniles and adults. Indeed these low sample sizes could explain the fact that $C$. axillaris $\hat{\lambda}$ in Khao Yai is $<1$; if five of the seven adults that died (out of 159 individuals) had lived instead, $\hat{\lambda}$ in Khao Yai would equal 1.00. If we assume that $\hat{\lambda}$ in Khao Yai equals 1 (and adjust adult survivorship in the model to 
make this so), the relative differences in $C$. axillaris population growth rate $(\Delta \hat{\lambda})$ between Khao Yai and the increased-hunting scenarios (i.e., the other parks) drop by $\sim 20 \%$ from the values shown in Fig. 6 for each park scenario. Thus, if our baseline estimate of $C$. axillaris population growth rate in Khao Yai was biased low, true declines in $\hat{\lambda}$ across the increased-hunting scenarios would be lower than we report here. However, (1) there would still be statistically real declines in $\hat{\lambda}$ in parks with higher hunting, and (2) the drop in $\hat{\lambda}$ as hunting increases would remain monotonic and approximately linear.

The direct ecological impacts of hunting by humans in protected areas can be severe, and may in turn precipitate indirect negative effects on a widespread canopy tree. Even tree species such as $C$. axillaris, with multiple seed dispersers, are susceptible to the indirect effects of poaching if those mutualists are large mammals. The mere establishment of protected areas is insufficient to fulfill conservation goals. Effective enforcement, the active engagement of local people in protected area management, and education about the ecological effects of hunting are also required.

\section{ACKNOWLEDGMENTS}

We thank the Royal Forest Department, the National Research Council of Thailand, and the chiefs and staffs of Khao Yai, Nam Nao, Doi Inthanon, and Doi Suthep-Pui National Parks. Funding for this work was provided by EPASTAR, NSF-DDIG, and Sigma Xi fellowships to J. F. Brodie, by the Denver Zoological Foundation, and by the Universities of Montana and Washington. Funding to W. Y. Brockelman was supplied by the Biodiversity Research and Training Program, BIOTEC, Bangkok. We thank T. Martin, L. S. Mills, R. Callaway, E. Crone, M. Kauffman, and an anonymous reviewer for critique of previous versions of the manuscript.

\section{Literature Cited}

Baum, J. K., R. A. Myers, D. G. Kehler, B. Worm, S. J. Harley, and P. A. Doherty. 2003. Collapse and conservation of shark populations in the northwest Atlantic. Science 299:389-392.

Bennett, E. L., A. J. Nyaoi, and J. Sompud. 2000. Saving Borneo's bacon: the sustainability of hunting in Sarawak and Sabah. Pages 305-324 in J. G. Robinson and E. L. Bennett, editors. Hunting for sustainability in tropical forests. Columbia University Press, New York, New York, USA.

Bennett, E. L., and M. Rao. 2002. Wild meat consumption in Asian tropical forest countries: Is this a glimpse of the future for Africa? Pages 39-44 in S. Mainka and M. Trivedi, editors. Links between biodiversity, conservation, livelihoods and food security: the sustainable use of wild species for meat. IUCN, Gland, Switzerland.

Bennett, L. T., P. F. English, and R. McCain. 1940. The study of deer populations by the use of pellet-group counts. Journal of Wildlife Management 4:398-403.

Bodmer, R. 1991. Strategies of seed dispersal and seed predation in Amazonian ungulates. Biotropica 23:255-261.

Brechin, S. R., P. R. Wilshusen, C. L. Fortwangler, and P. C. West. 2003. Contested nature. State University of New York Press, Albany, New York, USA.

Brockelman, W. Y., and R. Ali. 1987. Methods of surveying and sampling forest primate populations. Pages 23-62 in C. W. Marsh and R. A. Mittermeier, editors. Primate conservation in the tropical rain forest. Alan R. Liss, New York, New York, USA.
Brockelman, W. Y., and S. Srikosamatara. 1993. Estimation of density of gibbon groups by use of loud songs. American Journal of Primatology 29:93-108.

Brodie, J. 2006. An experimentally determined persistence rate correction factor for scat-based abundance indices. Wildlife Society Bulletin 34:1216-1219.

Caswell, H. 2001. Matrix population models. Second edition. Sinauer Associates, Sunderland, Massachusetts, USA.

Chapman, C. A., and L. J. Chapman. 1995. Survival without dispersers: seedling recruitment under parents. Conservation Biology 9:675-678.

Chapman, C. A., and D. A. Onderdonk. 1998. Forests without primates: primate/plant codependency. American Journal of Primatology 45:127-141.

Cordeiro, N. J., and H. F. Howe. 2003. Forest fragmentation severs mutualism between seed dispersers and an endemic African tree. Proceedings of the National Academy of Sciences (USA) 100:14052-14056.

Corlett, R. T. 2007. The impact of hunting on the mammalian fauna of tropical Asian forests. Biotropica 39:292-303.

Crouse, D. T., L. B. Crowder, and H. Caswell. 1987. A stagebased population model for loggerhead sea turtles and implications for conservation. Ecology 68:1412-1423.

Dinerstein, E. 1982. Deer, plant phenology, and succession in the lowland forests of Nepal. Pages 272-288 in C. Wemmer, editor. Biology and management of the Cervidae. Smithsonian Institution Press, Washington, D.C., USA.

Estrada, A., R. Coates-Estrada, D. Meritt, Jr., S. Montiel, and D. Curiel. 1993. Patterns of frugivore species richness and abundance in forest islands and in agricultural habitats at Los Tuxtlas, Mexico. Vegetatio 107/108:245-257.

Fa, J. E., and C. A. Peres. 2001. Game vertebrate extraction in African and Neotropical forests: an intercontinental comparison. Pages 203-241 in J. D. Reynolds, G. M. Mace, K. H. Redford, and J. G. Robinson, editors. Conservation of exploited species. Cambridge University Press, Cambridge, UK.

Fa, J. E., C. A. Peres, and J. Meeuwig. 2001. Bushmeat exploitation in tropical forests: an intercontinental comparison. Conservation Biology 16:232-237.

Forget, P.-M., and P. A. Jansen. 2007. Hunting increases dispersal limitation in the tree Carapa procera, a nontimber forest product. Conservation Biology 21:106-113.

Frank, K. T., B. Petrie, J. S. Choi, and W. C. Leggett. 2005. Trophic cascades in a formerly cod-dominated ecosystem. Science 308:1621-1623.

Gardner, S., P. Sidisunthorn, and V. Anusarnsunthorn. 2000. A field guide to forest trees of northern Thailand. Kobfai Publishing Project, Bangkok, Thailand.

Gautier-Hion, A., et al. 1985. Fruit characteristics as a basis of fruit choice and seed dispersal in a tropical forest vertebrate community. Oecologia 65:324-337.

Howe, H. F. 1977. Bird activity and seed dispersal of a tropical wet forest tree. Ecology 58:539-550.

Howe, H. F., and M. N. Mariti. 2004. When seed dispersal matters. BioScience 54:651-660.

Howe, H. F., and J. Smallwood. 1982. Ecology of seed dispersal. Annual Review of Ecology and Systematics 13: 201-228.

Kunsakorn, P. 2001. Fruit production and seed dispersal of Choerospondias axillaris (Anacardiaceae) in Khao Yai National Park, Thailand. Thesis. Mahidol University, Bangkok, Thailand.

Leimgruber, P., J. B. Gagnon, C. Wemmer, D. S. Kelly, M. A. Songer, and E. R. Selig. 2003. Fragmentation of Asia's remaining wildlands: implications for Asian elephant conservation. Animal Conservation 6:347-359.

Lynam, A. J., P. D. Round, and W. Y. Brockelman. 2006. Status of birds and large mammals in Thailand's Dong Phayayen-Khao Yai Forest Complex. Biodiversity Research 
and Training Program and Wildlife Conservation Society, Bangkok, Thailand.

Maxwell, J. F., and S. Elliott. 2001. Vegetation and vascular flora of Doi Sutep-Pui National Park, northern Thailand. Thai Studies in Biodiversity Number 5, Bangkok, Thailand.

Milner-Gulland, E. J., et al. 2003. Wild meat: the big picture. Trends in Ecology and Evolution 18:351-357.

Milton, K. 1991. Leaf change and fruit production in six Neotropical Moraceae species. Journal of Ecology 79:1-26.

Myers, R. A., and B. Worm. 2003. Rapid worldwide depletion of predatory fish communities. Nature 423:280-283.

Neff, D. J. 1968. The pellet group count techniques for big game trends, census, and distribution: a review. Journal of Wildlife Management 32:597-614.

O'Brien, T. G., and M. F. Kinnaird. 2000. Differential vulnerability of large birds and mammals to hunting in north Sulawesi, Indonesia, and the outlook for the future. Pages 199-213 in J. G. Robinson and E. L. Bennett, editors. Hunting for sustainability in tropical forests. Columbia University Press, New York, New York, USA.

Peres, C. A. 1999. Nonvolant mammal community structure in different Amazonian forest types. Pages 564-581 in J. F. Eisenberg and K. H. Redford, editors. Mammals of the Neotropics. Volume 3. University of Chicago Press, Chicago, Illinois, USA.

Peres, C. A. 2000. Evaluating the impact and sustainability of subsistence hunting at multiple Amazonian forest sites. Pages 31-56 in J. G. Robinson and E. L. Bennett, editors. Hunting for sustainability in tropical forests. Columbia University Press, New York, New York, USA.

Peres, C. A., and E. Palacios. 2007. Basin-wide effects of game harvest on vertebrate population densities in Amazonian forests: implications for animal-mediated seed dispersal. Biotropica 39:304-315.

Pfister, C. A. 1998. Patterns of variance in stage-structured populations: evolutionary predictions and ecological implications. Proceedings of the National Academy of Sciences (USA) 95:213-218.

Redford, K. H. 1992. The empty forest. BioScience 42:412-422.

Robinson, J. G., and E. L. Bennett. 2000. Hunting for sustainability in tropical forests. Columbia University Press, New York, New York, USA.

Robinson, J. G., and E. L. Bennett. 2004. Having your wildlife and eating it too: an analysis of hunting sustainability across tropical ecosystems. Animal Conservation 7:397-408.

Round, P. 1984. The status and conservation of the bird community in Doi Suthep-Pui National Park, north-west Thailand. Natural History Bulletin of the Siam Society 32: $21-46$.

Silva, J. N., and M. Tabarelli. 2000. Tree species impoverishment and the future flora of the Atlantic forest of northeast Brazil. Nature 404:72-74.
Silvertown, J., M. Franco, I. Pisanty, and A. Mendoza. 1993. Comparative plant demography: relative importance of lifecycle components to the finite rate of increase of woody and herbaceous perennials. Journal of Ecology 81:465-476.

Smitinand, T. 1977. Plants of Khao Yai National Park. New Thammada Press, Bangkok, Thailand.

Springer, A. M., J. A. Estes, G. B. Van Vliet, T. M. Williams, D. F. Doak, E. M. Danner, K. A. Forney, and B. Pfister. 2003. Sequential megafaunal collapse in the North Pacific Ocean: an ongoing legacy of industrial whaling? Proceedings of the National Academy of Sciences (USA) 100:1222312228.

Stoner, K. E., P. Riba-Hernandez, K. Vulinec, and J. E. Lambert. 2007a. The role of mammals in creating and modifying seedshadows in tropical forests and some possible consequences of their elimination. Biotropica 39:316-327.

Stoner, K. E., K. Vulinec, S. J. Wright, and C. A. Peres. $2007 b$. Hunting and plant community dynamics in tropical forests: a synthesis and future directions. Biotropica 39:385-392.

Tapper, P.-G. 1996. Long-term patterns of mast fruiting in Fraxinus excelsior. Ecology 77:2567-2572.

Terborgh, J., L. Lopez, P. Nunez, M. Rao, G. Shahabuddin, G. Orihuela, M. Riveros, R. Ascanio, G. H. Adler, T. D. Lambert, and L. Balbas. 2001. Ecological meltdown in predator-free forest fragments. Science 294:1923-1926.

Tungittiplakorn, W., and P. Dearden. 2002. Hunting and wildlife use in some Hmong communities in northern Thailand. Natural History Bulletin of the Siam Society 50: $57-73$.

Tutin, C. E. G., and M. Fernandez. 1993. Relationships between minimum temperature and fruit production in some tropical forest trees in Gabon. Journal of Tropical Ecology 9: 241-248.

Wang, B. C., V. L. Sork, M. T. Leong, and T. B. Smith. 2007. Hunting of mammals reduces seed removal and dispersal of the Afrotropical tree Antrocaryon klaineanum (Anacardiaceae). Biotropica 39:340-347.

WCS. 2002. Hunting and wildlife trade in tropical and subtropical Asia: identifying gaps and developing strategies. Wildlife Conservation Society, New York, New York, USA.

Wright, J. S., H. Zeballos, I. Dominguez, M. M. Gallardo, C. M. Moreno, and R. Ibanez. 2000. Poachers alter mammal abundance, seed dispersal, and seed predation in a Neotropical forest. Conservation Biology 14:227-239.

Wright, S. J., and H. C. Duber. 2001. Poachers and forest fragmentation alter seed dispersal, seed survival, and seedling recruitment in the palm Attalea butyraceae, with implications for tropical tree diversity. Biotropica 33:583-595.

Wright, S. J., A. Hernandez, and R. Condit. 2007. The bushmeat harvest alters seedling banks by favoring lianas, large seeds, and seeds dispersed by bats, birds, and wind. Biotropica 39:363-371. 